\title{
Retos en un mundo en crisis para nuevos profesionales
}

Carlos Acevedo'

Presidente Banco Central de Reserva

\section{RESUMEN}

El mundo apenas empieza a salir de la peor crisis económica de los últimos 80 años, pero se encuentra todavía como un enfermo convaleciente, que se recupera de un grave quebranto de salud, pero que todavía no se encuentra lo suficientemente fuerte como para garantizar que no pueda sufrir una recaída. A nivel internacional se habla incluso de la posibilidad de un "double dip", es decir, una recaída de la economía mundial, causada por la inestabilidad de los mercados financieros internacionales, debida principalmente a las amenazas fiscales en la zona del euro, y a la lentitud con que ha procedido la recuperación económica global. Todavía hay grandes nubarrones en el horizonte.

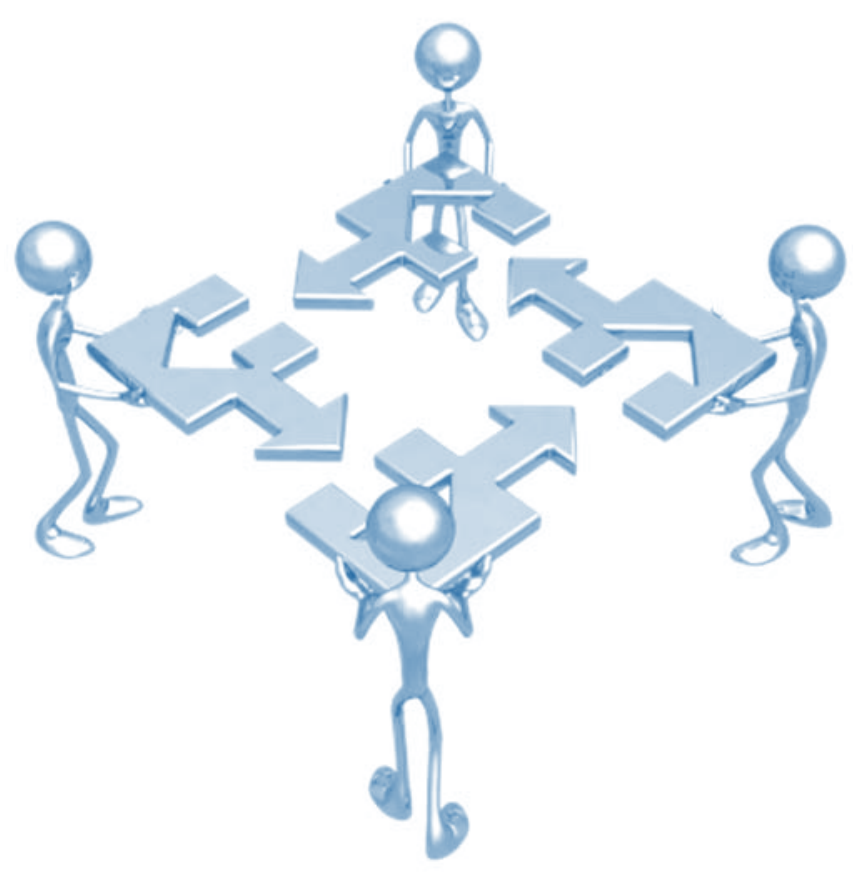

Tiempos verdaderamente difíciles, a nivel mundial y nacional.

Eu su columna habitual del New York Times del lunes reKrugman, señalaba que bien podríamos estar encaminándonos hacia lo qué el considera la tercera Depresión Larga desde el último cuarto del siglo XIX, y la Gran Depresión de los años 30 del siglo pasado. El hecho de que la economía mundial haya empezado a mostrar algunas señales de recuperación no garantiza que no pueda darse esta tercera Depresión mundial. Ni la Depresión Larga del siglo XIX ni la Gran Depresión del siglo XIX fueron períodos de declive económico ininterrumpido; por el contrario, ambas depresiones incluyeron períodos de crecimiento económico, pero estos períodos fueron insuficientes para re-

\footnotetext{
1 Discurso dado por el Dr. Carlos Acevedo, en su calidad de invitado especial, en ocasión de la graduación de Maestrías de la Universidad Tecnológica de El Salvador, 2010.
} 
vertir la dinámica de profundo deterioro económico registrado en esas dos fases depresivas de la economía mundial.

A nivel nacional también vivimos una crisis que tiene pocos precedentes. En gran parte, nuestra crisis económica interna se debe al contagio de la crisis internacional principal de la crisis de la economía norteamericana, pero también se debe a que como país no hemos impulsado las políticas públicas necesarias para alcanzar tasas de crecimiento sostenido y brindar un mayor nivel de bienestar para nuestra población. Recientemente, se ha escuchado varias voces lamentándose de que debido a la situación de inseguridad prevaleciente en el país, la inversión privada ha caído.

Esta situación no es en modo alguno novedosa. En 1999, trabajando en FUSADES como gerente de estudios macroeconómicos, la institución invitó a sebastián Edwards para coordinar la estrategia de desarrollo económico y social para 19992004 que se le presentaría al Presidente Flores. Para poner en contexto la figura de Sebastián Edwards, recordemos que, luego de haber sido uno de los principales alumnos latinoamericanos de Arnold Harberger en la universidad de Chicago, Sebastián Edwards ocupó varios cargos prominentes a nivel internacional, como el de economista jefe del Banco Mundial para América Latina, y es desde hace varios años profesor titular en la escue- la de negocios de la universidad de California en Los Angeles (UCLA). Pues bien, ya en 1999 Sebastián Edwards señalaba a FUSADES que los niveles de inversión en general, y de inversión privada, específicamente, eran demasiado bajos en El Salvador y que con esos niveles de inversión nuestro país no iría a ningún lado. Sebastián Edwards se refería a los datos de inversión de la segunda mitad de los 1990. Ello implica que El Salvador tiene por lo menos 15 años de mantener tasas de inversión muy bajas.

Cinco años más tarde, en 2004, FUSADES contrató a otro economista latinoamericano de reputación internacional, Ricardo Hausmann, ex-ministro de planificación de Venezuela, ex - economista jefe del Banco Interamericano de Desarrollo (BID) y actual director del Centro para el Desarrollo Internacional de la universidad de Harvard, para que coordinara la elaboración de la estrategia quinquenal 2004-2009, que le sería presentada al presidente Saca. En una ilustrativa reunión con la junta directiva de FUSADES, Ricardo Hausmann les planteó un escenario hipotético: "Supongamos-decíaque yo soy un inversionista que llega a El Salvador con \$20 millones en los bolsillos buscando oportunidades de inversión, en qué me aconsejarían ustedes invertir?" Ninguno de los empresarios ahí presentes pudo darle una sola idea para llevar a cabo una inversión rentable.

El problema de la baja inversión no es en modo alguno nuevo, como tampoco lo son varios de los otros graves problemas que afectan el clima de negocios en el país, como el tema de la inseguridad. Ya también desde la segunda mitad de Ios noventa, esto es, desde hace por lo menos 15 años, los empresarios salvadoreños han venido señalando recu- 
rrentemente en las encuestas de clima de negocios realizadas por organismos como el Banco Mundial, que la situación de violencia y delincuencia constituye el principal obstáculo para invertir en el país, y que es en El Salvador donde este obstáculo tiene mayores dimensiones entre los países de América Latina.

Como resultado de los bajos niveles de inversión y del desmantelamiento de nuestro aparato productivo nacional, nos hemos convertido en un país eminentemente consumista. Somos el tercer país en el mundo con el consumo privado más alto como porcentaje del PIB, después de Liberia y Lesoto. Nuestro consumo agregado como país es mayor que el PIB. Consumimos más de lo que producimos. Los desarrollos ocurridos en el ámbito financiero desde la dolarización han reforzado esta distorsión estructural. Lo vemos por ejemplo en la estructura de la cartera de crédito del sistema bancario. Tan sólo los préstamos personales equivalente a más del doble de los créditos a la agricultura y a la industria combinados.

Sin duda ustedes han coronado con muchas ilusiones esta importante fase de su trayectoria profesional. Sin duda también, el diploma que ahora van a recibir les ha costado grandes sacrificios, económicos y personales. Como les mencionaba hace un momento, el entorno económico en el que les está tocando desempeñarse no es en modo alguno fácil. El mercado la- boral, en particular, es cada vez más difícil y complicado. Las presiones competitivas son cada vez mayores. Hace algunos años, la obtención de un título de maestría era casi un mecanismo automático para lograra un ascenso laboral inmediato. Ahora, muchas consideran que el tener una maestría ha pasado a ser una condición para no perder el empleo que ya se tiene.

Por eso es importante tener claros los desafíos que los esperan. Más allá de sus papis expectativas y las de sus amigos y familiares, el país espera mucho de ustedes. Ustedes pertenecen a una minoría de privilegiados que no sólo ha logrado obtener un título universitario sino que ahora están también coronando exitosamente un buen programa de maestría, en un país donde el promedio de la población ni siquiera ha logrado completar la

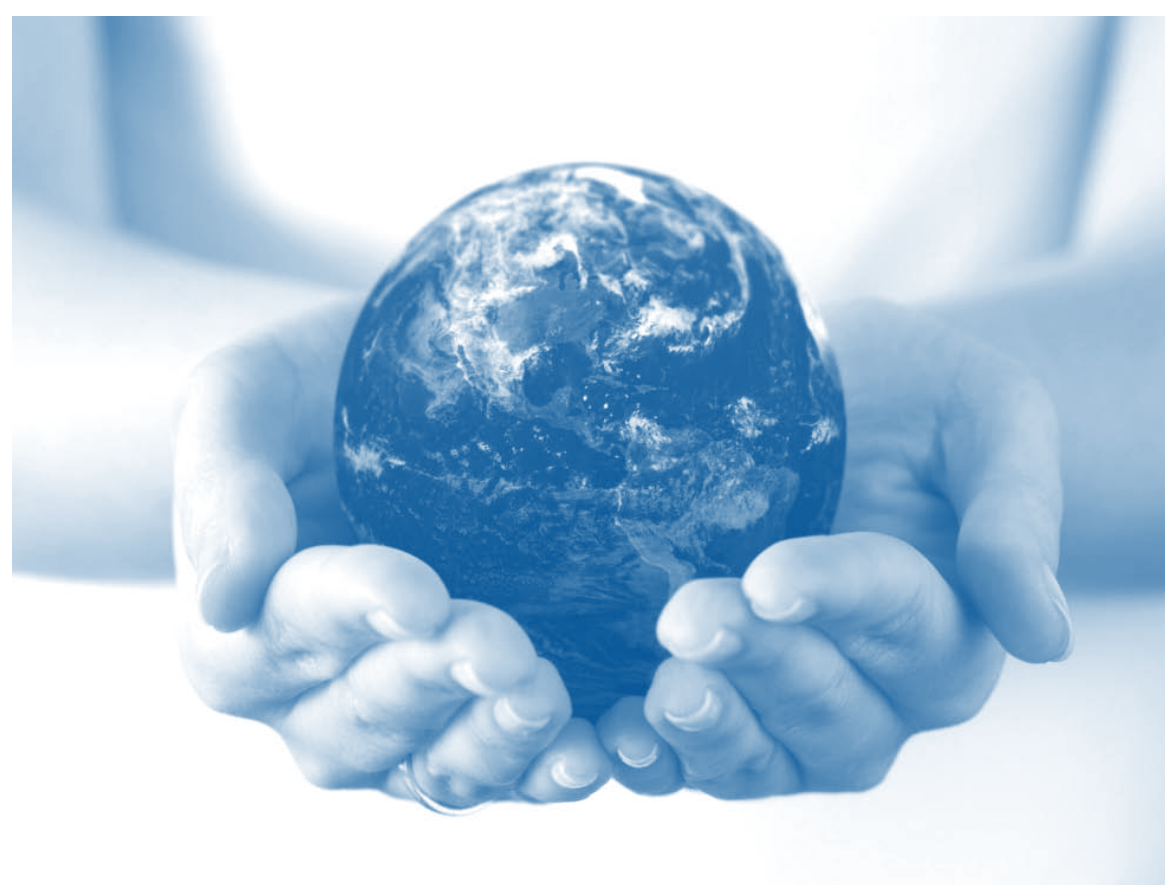

educación primaria. "A quien mucho se le ha dado, mucho se le va a exigir", nos dice el Evangelio. Todos nosotros hemos recibido mucho y estamos por tanto obligados a devolver mucho al país.

La UTEC les ha provisto con una buena caja de herramientas técnicas para hacerle frente a estos desafíos, pero estoy seguro de que también ha tratado de inculcar en ustedes valores y actitudes que van más allá de las consideraciones inmediatas de rentabilidad financiera que han sabido imperar en el mundo de los negocios. De hecho, hemos visto en años recientes como los programas de maestría que ponen un mayor énfasis en los principios éticos han empezado a escalar posiciones en los rankings de mejores escuelas de negocios del mundo. Ser ético no sólo es algo bueno en sí mismo, sino que puede ser también un buen negocio. 